\title{
Scientific research as a service for our patients: utopia or necessity?
}

\author{
Nicolino Ambrosino
}

Received: 3 January 2012/ Accepted: 29 February 2012/Published online: 20 March 2012

(C) Springer-Verlag 2012

Clinical research has led to great progress in the care of patients. Scientific research principles have been applied to medical research, nevertheless the results of this human activity are somehow more discussed than in other fields of science. Evidence-based medicine (EBM) is a concept and a function used in human medicine since the 90 s to apply research results to medical practice. This concept refers to the careful, transparent and wise use of current best evidence from research for the individual care of patients [1]. After an early enthusiastic welcome, the real value of EBM in clinical practice has been recently questioned.

Pro. According to supporters, the aim of EBM is to provide new tools to assist clinicians, and new challenges to practitioners. Therefore, EBM represents a highly individualised, patient-centered approach to clinical decision making. Using EBM clinicians should be able to care at best their patients, looking for, and interpreting the quality of scientific evidence. Furthermore, clinicians should always take into account patients' values and preferences in the decision-making process [2]. These supporters recognise that there is the need to integrate different types of evidence from a range of sources to improve decisions about individual patients, to include guidelines in personal clinical practice of the individual patient [1]. Supporters conclude that effective teaching of EBM to medical students is important for lifelong self-directed learning [3].

N. Ambrosino

Pulmonary Rehabilitation and Weaning Center,

Auxilium Vitae, Volterra, Italy

N. Ambrosino $(\square)$

U.O. Pneumologia, Dipartimento Cardio-Toracico,

Azienda Ospedaliero-Universitaria Pisana,

Via Paradisa 2, Cisanello, 56124 Pisa, Italy

e-mail: n.ambrosino@ao-pisa.toscana.it
Nevertheless, there is evidence that at the undergraduate level, self-perceived does not correlate well with objectively assessed competence in EBM [4].

Con. The objection of EBM less enthusiastic supporters is that a wise physician should make individually tailored decisions on a background of scientific theory which might be seen as a source of medical certainty [5].

\section{Clinical research versus clinical practice}

How clinical research results impact on current clinical practice? We can say that in the current practice physiological and clinical effects not always run in the same lane [6]. An example of this assumption is the use of bronchodilators, that is drugs able to reduce airway obstruction, in COPD, a disease defined as "a preventable and treatable disease.... Its pulmonary component is characterised by airflow limitation that is not fully reversible..." [7]. This means that by definition the specific physiologic result of a drug (bronchodilation) might not be fully effective in stable COPD. Nevertheless, clinical studies indicate the usefulness of long-term bronchodilators (and these drugs are actually used) in stable COPD [8].

\section{Innovation versus dissemination}

What is the influence of EBM on clinical decisions?

Example 1 UPLIFT [9] and TORCH, [10] amongst the largest and most ambitious trials on COPD patients, were disappointing as for their proposed primary outcomes. In summary, the results of the TORCH and UPLIFT trials are unlikely to have induced major changes in current 
prescribing practices. For a number of reasons, it would seem unlikely that confirmation trials will ever be attempted. However, all guidelines include drugs evaluated in such trials in the treatment panel of COPD [11, 12].

Example 2 Recent literature in mechanical ventilation (MV) includes strong evidence from randomised trials. To assess the influence of randomised trials on clinical practice a prospective international observational cohort study, on more than 4,000 consecutive patients receiving $\mathrm{MV}$ in intensive care units (ICUs) over a 1-month period, compared data from the ICUs that also participated in a previous (1998) cohort study [13]. Results showed that clinical tools and methods suggested by randomised clinical trials were increasingly used in the ICUs. As an example in 2004 compared with 1998, the use of noninvasive ventilation $[13,14]$ increased (11.1 vs. $4.4 \%$ ), a result recently confirmed [15]. Among patients with acute respiratory distress syndrome, on the basis of data of randomised trial [16], there was a change of modality of ventilation. The strong concordance of predicted and observed practice changes suggested that randomised trial results have advanced MV practices internationally [13].

\section{Actual and perceived quality of care}

Clinical decisions should include consideration of the patient's clinical and physical circumstances to establish what treatment options are available. The latter need to keep into account research evidence on efficacy, effectiveness, and efficiency of the therapeutical options. Furthermore, the clinician must also consider the patient's preferences and likely actions. Finally, clinical expertise must pool these considerations together and recommend the treatment that the patient prefers [17]. Therefore, the patient's perception of quality of care is crucial. Nevertheless, patient's perception is deeply influenced by media. Indeed in USA, Diem et al. watched all the episodes of the television programs ER and Chicago Hope during the 1994-1995 viewing season and 50 consecutive episodes of Rescue 911 broadcast over a 3-month period in 1995. They identified all occurrences of Cardio Pulmonary Resuscitation (CPR) in each episode and recorded the causes of cardiac arrest, the identifiable demographic characteristics of the patients, the underlying illnesses, and the outcomes. The survival rates in that study were significantly higher than the most optimistic survival rates in the medical literature. As a consequence, CPR fiction on television may lead the viewing public to have an unrealistic impression of CPR and its chances for success [18]. Given the differences between possibilities of real life medicine and expectations supported by suggested miracles, it is not surprising that media may contribute to increasing legal controversies for malpractice [19].

\section{Objectivity and independence}

The approval, prescribing, and safety of drug prescription involve a concerted action of science, regulatory law, clinical judgment, business, and politics. It is not easy to be sure that scientific criteria prevail in such a complex process. Due to economic restraints industry is the main support of clinical research. As a consequence, it will be important for the scientific community to remain independent, conduct rigorous analyses, and make all efforts in order that drug-review decisions are driven solely by the data [20]. Indeed with the bias of being affiliated of a Cochrane Centre, Jørgensen et al. [21] compared the methodological quality and conclusions in Cochrane reviews with those in industry-supported meta-analyses and other meta-analyses of the same drugs. A systematic review comparing pairs of meta-analyses that studied the same two drugs in the same disease and were published within 2 years of each other was performed. On a 0-7 scale, the median quality score was seven for Cochrane reviews and three for other reviews. Compared with industry-supported reviews and reviews with undeclared support, Cochrane reviews had more often considered the potential for bias. The industry-supported reviews that had conclusions recommended the experimental drug without reservations, compared with none of the Cochrane reviews, although the estimated treatment effect was similar on average. Reviews with undeclared support and reviews with no profit support or no support had conclusions that were similar in cautiousness to the Cochrane reviews. The conclusion was that industry-supported reviews of drugs should be read with caution as they were less transparent, had few reservations about methodological limitations of the included trials, and had more favourable conclusions than the corresponding Cochrane reviews [21].

In conclusion, patients need scientific research, scientific research needs patients' ethical control. Additional problems of industry-supported trials are related to:

1. Ownership of research results. It is well-known that most of "negative" results of trials are not published, thus introducing a bias potentially relevant, in evaluation of results of related meta-analyses on their turn influencing Guidelines.

2. Availability of resources for research in rare diseases field. This issue is related strictly to "no profit" research, which should be supported by independent networks, requiring funding from National States or International Consortia. 
Conflict of interest None.

\section{References}

1. Croft P, Malmivaara A, van Tulder M (2011) The pros and cons of evidence-based medicine. Spine 36:E1121-E1125

2. Karanicolas PJ, Kunz R, Guyatt GH (2008) Point: evidence-based medicine has a sound scientific base. Chest 133:1067-1071

3. Sastre EA, Denny JC, McCoy JA, McCoy AB, Spickard A (2011) Teaching evidence-based medicine: impact on students' literature use and inpatient clinical documentation. Med Teach 33(6):e306e312

4. Lai NM, Teng CL (2011) Self-perceived competence correlates poorly with objectively measured competence in evidence based medicine among medical students. BMC Med Educ 11:25

5. Tobin MJ (2008) Counterpoint: evidence-based medicine lacks a sound scientific base. Chest 133:1071-1074

6. Ambrosino N (2011) The case for inspiratory muscle training on COPD. Eur Resp J 37:233-235

7. Global Initiative for Chronic Obstructive Lung Disease (2009) Global strategy for the diagnosis, management and prevention of chronic obstructive pulmonary disease (updated 2009). Bethesda, National Heart, Lung and Blood Institute. http://www.goldcopd.com

8. Celli BR, Thomas NE, Anderson JA, Ferguson GT, Jenkins CR, Jones PW et al (2008) Effect of pharmacotherapy on rate of decline of lung function in chronic obstructive pulmonary disease. Results from the TORCH study. Am J Respir Crit Care Med 178:332-338

9. Celli B, Decramer M, Kesten S, Liu D, Mehra S, Tashkin DP, UPLIFT study investigators (2009) Mortality in the 4-year trial of tiotropium (UPLIFT) in patients with chronic obstructive pulmonary disease. Am J Respir Crit Care Med 180:948-955

10. Calverley PM, Anderson JA, Celli B, Ferguson GT, Jenkins C, Jones PW et al (2007) Salmeterol and fluticasone propionate and survival in chronic obstructive pulmonary disease. N Engl J Med 356:775-789
11. Niewoehner DE (2009) TORCH and UPLIFT: what has been learned from the COPD "Mega-Trials"? J Chron Obstr Pulm Dis $6: 1-3$

12. Singh S, Loke YK, Enright PL, Furberg CD (2011) Mortality associated with tiotropium mist inhaler in patients with chronic obstructive pulmonary disease: systematic review and metaanalysis of randomised controlled trials. BMJ 342:d3215

13. Esteban A, Ferguson ND, Meade MO, Frutos-Vivar F, Apezteguia C, Brochard L et al (2008) Evolution of mechanical ventilation in response to clinical research. Am J Respir Crit Care Med 177:170-177

14. Ambrosino N, Vagheggini G (2008) Noninvasive positive pressure ventilation in the acute care setting: where are we? Eur Respir J 31:874-886

15. Chandra D, Stamm JA, Taylor B, Ramos RM, Satterwhite L, Krishnan JA et al (2012) Outcomes of noninvasive ventilation for acute exacerbations of chronic obstructive pulmonary disease in the United States, 1998-2008. Am J Respir Crit Care Med 185:152-159

16. Acute Respiratory Distress Syndrome Network (2000) Ventilation with lower tidal volumes as compared with traditional tidal volumes for acute lung injury and the acute respiratory distress syndrome. N Engl J Med 342:1301-1308

17. Haynes RB, Devereaux PJ, Guyatt GH (2002) Physicians' and patients' choices in evidence based practice. BMJ 324(7350): 1350

18. Diem SJ, Lantos JD, Tulsky JA (1996) Cardiopulmonary resuscitation on television. Miracles and misinformation. N Engl J Med 334:1578-1582

19. Jena AB, Seabury S, Lakdawalla D, Chandra A (2011) Malpractice risk according to physician specialty. N Engl J Med 365:629-636

20. Avorn J (2007) Keeping science on top in drug evaluation. N Engl J Med 357:633-635

21. Jørgensen AW, Hilden J, Gøtzsche PC (2006) Cochrane reviews compared with industry supported meta-analyses and other metaanalyses of the same drugs: systematic review. BMJ 333(7572):782 